\title{
Dromoscopy and Philosophy
}

\section{Tomas Hauer*}

Department of Philosophy and Religious Studies, University of Zilina, Slovakia

\begin{abstract}
Dromology originates from the Greek word dromos. Hence, dromology is the science of the ride, the journey, the drive, the way. This means that speed and riches are totally linked concepts. And that the history of the world is not only about the political economy of riches, that is, wealth, money, capital, but also about the political economy of speed. Virilio's texts deal with the impact of speed, disaster and accident on the contemporary world. Vehicles of speed create new dromospheric chronology, new tracks and nodal points (ports, roads, airports, telecommunications etc.) through which things, goods, money, weapons, people or information will start flowing within a different structure. The result is a victory of the new logistics of perception, new dromoscopy. Indirect inner light of screens is our second sun. The text analyses Virilio's proposition that technical apparatus came into play employing active wave optics and the speed of indirect light, which contributed to the emergence dromoscopic order of vision, which completely transformed the existing logistics of perception of reality.
\end{abstract}

Keywords: Dromology; Scientific structures of reality; Technical images; Logistics of perception; Speed; Technological devices

\section{Introduction}

In the first third of the $20^{\text {th }}$ century, representation - or sign representation of reality, or possibly sign substitution of reality, was a large meta-theoretical problem of physical theory, however, almost immediately, it became a central issue of emerging philosophy of language. In fact, it turned out, how strong the bond between the grammar of language and scientific constructions of reality was, how the possibilities of language expression conditioned and restricted the construction of scientific knowledge as well as its communication. Philosophy of science and philosophy of language began differentiating the two languages used in science: the current language, only slightly modified into a research tool, and the language of mathematics, which meets the highest requirements of describability and clarity but only within the mathematized theory. Philosophy of science and philosophy of language focused, among other things, on the same problem - the problem of language expression of phenomena beyond everyday experience, whether it was phenomena of quantum physics, or linguistic or semiotic phenomena.

In about the same time, natural sciences, which raised the analogous problem of representation of reality by natural science theory, also found themselves in a similar situation as philosophy. The question was whether, for example, the physical theory of mechanics really shows or represents the studied reality itself, or whether it is only one of its possible images or representations. In this meta-theoretical discussion, the concepts of picture and representation performed the same function as the concept of representation in philosophy. The disputes about the concept of image and character of representation in physics are quite understandable. They could answer (and, in fact, they have already answered) the question what is really knowledge in the natural sciences? Mach's concept of elimination of metaphysics from science [1], is interesting even today because it contains elements around which philosophical and meta theoretical views grouped later. One of these elements is the problem of the concept of picture and the related concept of "representation". It is a basic problem, whose solution modifies the conception of scientific theory and scientific knowledge in general. In this context, it is necessary to mention Mach's harsh criticism "of metaphysical concepts in Newtonian mechanics, for example, according to Mach, the notion of absolute time does not have any practical nor scientific value. The goal of natural sciences is the search for relationships between phenomena and subsequent mathematical description of these relationships or functions [2]. Only this method of scientific work, based on empiricism, logic and mathematics, is able to resist the penetration of metaphysics into science. This method of scientific work must definitively eliminate metaphysical issues.

Ludwig Boltzmann also intensively considered the status of the concept of the picture [3], both in terms of its relation to the theoretical concepts and the experience, and in terms of the nature of the representation. Like Hertz, Boltzmann understood pictures as imitating certain types of connections and as "symbols of a method of connecting things". With respect to representation and its outcome, the picture, he emphasized structural relationships because he considered them not only essential, but also graspable by logic and mathematics. What is then the scientific theory? According to Boltzmann, it is "a pure spiritual inner view" of the world, "construction", whose cradle is the imagination, and whose educator is the intellect. In comparison with Mach, who prevented penetration of "constructions", "imagination" and "modelling" into science, Boltzmann proceeds not even as a metatheorist, but directly as an artist. He convinces us that the scientific theory cannot do without a non-empirical hypothesis (metaphysics) that only a subjectively speculative construction can lead physics to other mysteries as well as the results. In the next section, we will focus on the analysis of the two theories that have been formulated as a philosophical response to the transformation of the concept of picture in the contemporary philosophical theory. This is the case of Vilem Flusser and his concept of technical images and of Paul Virilio and his science of speed, called dromology.

*Corresponding author: Hauer T, Department of Philosophy and Religious Studies, Faculty of Humanities, University of Zilina, Slovakia, Tel: +421 41513 6113; E-mail: thauer777@gmail.com

Received December 26, 2016; Accepted January 03, 2017; Published January 09, 2017

Citation: Hauer T (2017) Dromoscopy and Philosophy. J Mass Communicat Journalism 7: 326. doi: 10.4172/2165-7912.1000326

Copyright: (c) 2016 Hauer T. This is an open-access article distributed under the terms of the Creative Commons Attribution License, which permits unrestricted use, distribution, and reproduction in any medium, provided the original author and source are credited. 


\section{Technical Images as Visualized Concepts}

The term technical image (according to the media theorist Vilem Flusser, its first form was photography, and the last form by now have been images projected in all possible forms of screens, monitors and displays, including holograms) can be understood as a term referring to the beginning of a new age, which is coming after the age of linear writing. Historically as well as ontologically, compared to the previous tradition, these technical images mean rupture, a breakthrough. The image is divided into a stream of flowing numbers, but the essence of the image blurs in this current, it fades to its outside. In one image, there is an intermediate collision of coded characters with the image that produces this code, of an abstract number with the human body, of an image-surface with an image-depth. Apparatuses [4] that create the digital nature of the computer code systematically produce a number as the real and unique fundament of a digital image-technical image by attributing it the autonomous spatial vastness of the "body" of the new image. Fetishisation of numbers as a paradoxical spatial object is thematised through simulated rolling on the monitor as if the camera passes through the number. The light mode based on the principles of vision and remote control, instantaneous speed and immediate feedback among everything becomes the decisive line of digital media dispositive. We live in a world where the highest function of sign is to allow the reality to disappear, and at the same time, to mask this disappearance at that [5].

At the beginning of Flusser's philosophy of technical images, we encounter a cultural-sociological model where the author in five stages indicates the changes in relationship between man and the world, depending of the kind of the medium dominant for the particular historical epoch. This model is a ladder with five rungs. The mankind has climbed this ladder step by step - from the concrete to higher and higher abstractions. It is a model of cultural history and the alienation of man from the concrete experience of reality, a model in which man puts agents/tools - an image, text, technical image - between himself and the world. Flusser's model then describes a line-an image, text, technical image-while a traditional and technical image quantitatively differ [6]. Traditional images (such as cave paintings in Lascaux) are abstractions of the first order, if they abstract from the concrete world, while technical images are abstractions of the third order, they abstract from texts which abstract from traditional images which abstract from the concrete world. Technical image as an abstraction of the third order shows two qualities which differentiate it from abstractions of the first order (images) as well as from abstractions of the second order (texts) [7]. The technical image is an image produced by apparatuses. The difference between traditional and technical images, then, would be this. The first are observations of objects, the second computations of concepts [8]. Simply speaking, the technical image is, in fact, a visualized concept.

What do technical images mean, if they are not pictures in the usual sense? They are models. They are models that give form to a world and a consciousness that has disintegrated; they are meant to "inform" that world. To decode a technical image is not to decode what it shows but to read how it is programmed [9]. Therefore, a technical image is a tool whose function is - as with any intermediary tools or machines - to change reality. But what is reality? Material tools (a power plant or a car) change material reality. A technical image changes symbolic reality, it changes meanings, but as reality becomes reality only after meanings are assigned to it, a technical picture changes reality itself. Technical images again and again translate events into repeated screenings. The relationship between a technical image and a man, the operation between them, is therefore a central problem for any future theory and all the other issues must be addressed from here. This is the substance of Flusser's message.

\section{Dromocratic Revolution}

At the beginning of human history, there was only slowness slowness of life of agricultural society. Speed was created by people - merchants, soldiers, industrialists, scientists, engineers, computer scientists, bankers, etc. The present-day Identification with the speed may lead us to many different conclusions. The speed of our world is full of contradictions; the accelerated world conceals quite a few paradoxes. The question how much speed one needs and what rate of acceleration is tolerable for the economy, society and environment, remains unanswered. Speed began to gain positive value in the late 19th century. Dromology by Virilio seeks to analyse the ways that were crucial for the development of speed. He asks how the principle of acceleration in Central and Western Europe arose and explains the origin and method of spreading "various triggers of speed". Virilio's theory shows the far-reaching extent to which the speed conquered all and everything over the centuries: transportation and production, peace and war, men and women, urban and rural areas, work and leisure time, arts and commerce. Virilio clearly shows us how the principle of acceleration of the word has taken root in professional and private lives of individuals and societies in both good and bad sense, and mentality. Speed and wealth go hand in hand. To give a philosophical definition of speed, we can say that it is not a phenomenon, but rather the relationship between phenomena. In other words, it is relativity itself. Virilio's influential book - Speed and Politics - analyses new problems resulting from the fact that the development of industrial capitalism has reached the stage in which wealth and power in society have been interconnected with ever increasing speed. In view of Virilio's statement that wealth is an aspect of speed, it has become necessary to consider speed and all its aspects and consequences through a prism of a new discipline - dromology [10]. If time is money, as they say, then speed is power. You see it with velocity of the predators, of the cavalry, of railways, of ships and maritime power. So all my work has been about attempting to trace the dromocratic dimension of societies from ancient Greek to our present-day societies. All societies are pyramidal in nature. The higher speed belongs to the upper reaches of society, the slower to the bottom. The wealth pyramid is the replica of the velocity pyramid [11]. Virilio's dromoscopy [12] comes to an important conclusion when Virilio concludes analytical considerations of the third period by finding that at the beginning of reality there it is always the speed of light, but no longer the view, because the visible, produced by internal artificial light associated with active optics of technical media may resist the view. This visible effectively prevents natural vision, because it stands between reality illuminated by natural direct light and man, so it represents blinding, it is a "new and the last form of industrialization, industrialization of non-view" [13]. There are two things following from this: that mediation of light media cannot be escaped, and that mediation without speed is a myth. Co-creators of the dromosphere are light, speed and vision: where there is no light, there is no vision. Virilio creates dromology variant of the anthropic principle: space is not subject to vision, but it makes little sense to consider space for people without vision; time is not conditioned by vision, either, but it is consubstantial with light, because light is the shadow of absolute speed and absolute speed is the medium of time. The so-called objective reality, therefore, only exists through this medium called speed limit, the so-called objective reality arises through relativistic mediation. The term "so-called" is needed because "objectivity" arises here only 
through subjective perception. Vision is possible only because of the speed, "the speed is the light of light" [14]. Speed is not a phenomenon, but the relationship between phenomena. Dromology shows that the differences between phenomena result from the perception of different movements or awareness of speed. Unlike the perceived phenomena, however, speed is an abstraction. The fact-reality is established by differences, but these are differences in the movements of phenomena, differences in speed. The reality is established by differences that are established by speed. Hence the vital importance of examining speed is for understanding the nature of the contemporary society. Virilio's dromology adds a substantial supplement, according to which speed is associated with light as "the third interval" besides the traditional ontological categories of space and time, and it is therefore ontologically equal. Dromology asks what we actually do with rapidly changing phenomena, and what these rapidly changing phenomena do with us. Do we represent the structure, or construct the representation?

\section{Conclusion}

This paper critically analyses the theories of French cultural critic Paul Virilio and German media theorist Vilém Flusser. Vilém Flusser states in his key texts, that technical images become a dominant cognitive metaphor of the contemporary society. In the second, Virilio's texts deal with the impact of speed on the contemporary world. The development of means of transport used by people for the purpose of movement - from horse carts, railways and cars to planes, culminated by the arrival of digitalized audio-visual hypertext, the last "vehicle" that replaces its drivers' physical movement by total inertia. How does that historical succession starting with metabolic vehicles such as a horse, ships, railways, cars planes to the latest ways of tele- transfer, tele-presence and audio-visual vehicles, influence our presentday concept of the world?

\section{References}

1. Blackmore JT, Itagaki R, Tanaka S (2001) Ernst Mach's Vienna 1895-1930 Springer Science and Business Media.

2. Blackmore JT (1973) Ernst Mach - His Life, Work, and Influence. University of California.

3. Blackmore JT (1995) Ludwig Boltzman: His Later Life and Philosophy, 19001906. Springer Science and Business Media.

4. Latour B (1987) Science in Action: How to Follow Scientists and Engineers through Society. Harvard University Press.

5. Baudrillard J (1996) The Perfect Crime. Verso Books.

6. Flusser V (2011) Into the Universe of Technical Images. University of Minnesota Press pp: 14.

7. Flusser V (2000) Towards a Philosophy of Photography. Reaktion Books.

8. Flusser V(2011) Into the Universe of Technical Images, University of Minnesota Press, Minneapolis: London pp: 10.

9. Flusser $\mathrm{V}$ Into the Universe of Technical Images, University of Minnesota Press, Minneapolis: London, pp: 48.

10. Virilio $P$ (1999) The Politics of the Very Worst, trans. M. Cavaliere and S. Lotringer, New York: Semiotext(e) pp: 49.

11. Armitage J (2000) Paul Virilio: From Modernism to Hypermodernism and Beyond. London: Sage Publications pp: 35.

12. Armitage J (2001) Virilio Live (Selected Interiews). London: Sage Publications pp: 74.

13. Virilio P (2010) The University of Disaster. Polity Press pp: 80.

14. Virilio P (1991) The Aesthetitics of Disappearance. Semiotext(e). 